\title{
Helminth infection in the short-finned squid Illex coindetii (Cephalopoda, Ommastrephidae) off NW Spain
}

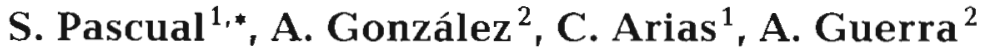 \\ 'Laboratorio de Parasitología, Facultad de Ciencias, Universidad de Vigo, Ap. 874 E-36200 Vigo, Spain \\ ${ }^{2}$ Instituto de Investigacions Mariñas (CSIC), Eduardo Cabello 6, E-36208 Vigo, Spain
}

\begin{abstract}
A survey of parasites in 600 short-finned squid Illex coindetii (Vérany, 1839) taken from 2 locations (north and south Galicia) off the northwestern Iberian Peninsula revealed the presence of numerous somatoxenous helminths. Three genera of Tetraphyllidean plerocercoids were represented (prevalences: Phyllobothrium sp., 45.7\%; Dinobothrium sp., 0.8\%; and Pelichnibothrium speciosum, $0.001 \%$ ); 1 Trypanorhynchidean metacestode was also present (Nybelinia yamagutij, $0.4 \%$ ). In addition, larval nematodes of Anisakis simplex (L3) were recorded (10.6\%). Abundance of infection was examined in relation to squid sex, standard length, maturity and locality. This analysis indicated that parasite infection was lower in the southern squids than in the northern squid group. Over the entire survey area, parasite infection showed a close positive correlation with hast life-cycle, often with the greatest number of parasites among the largest and highest maturity individuals ( $>18$ to $20 \mathrm{~cm}$; maturity stage $V$ ).
\end{abstract}

KEY WORDS: Illex coindetii - Northwestern Iberian Peninsula Helminth parasites

\section{INTRODUCTION}

Cephalopods represent $2.1 \%$ of total worldwide catches of marine organisms (Guerra \& PérezGándaras 1983). In spite of the economic importance of this fishery, relatively little is known about the hostparasite relationships of teuthoid cephalopods (see Hochberg 1990). Although no important specialized fishery for Illex coindetii exists off NW Spain, where squids are mainly a by-catch of multi-species trawl fisheries, it is surprising that there is no information about their parasite composition, bearing in mind the important role which they may play as a vital link for food-transmitted parasites in the Atlantic Ocean (Gaevskaya \& Nigmatullin 1975, 1977, 1978).

The long-term objective of our research program is to analyse the fishery implications of metazoan parasite infection in commercially important squids of

•E-mail: spascuas@seinv.cesqa.es northeastern Atlantic waters. To this end, in the present paper some aspects of the host-parasite relationship are examined. A possible local variability in degree of infection was also assessed in the light of the clearly different hydrographical conditions between northern and southern shelf areas off the Galician coast (Fraga et al. 1982).

\section{MATERIALS AND METHODS}

A total of 600 post-recruit Illex coindetii were collected from fishing grounds off the coast of Galicia (NW Spain) $\left(42^{\circ} 5^{\prime}\right.$ to $45^{\circ} 15^{\prime} \mathrm{N}, 7^{\circ} 30^{\prime}$ to $\left.9^{\circ} 20^{\prime} \mathrm{W}\right)$ between November 1992 and November 1993. Squid samples were obtained from commercial landings and separated into 2 groups according to the area where they were caught, the north group $(179.62 \pm 26.77 \mathrm{~mm}$ long) comprising all squids collected from Ribadeo to Finisterre, and the south group $(163.44 \pm 33.27 \mathrm{~mm}$ long) formed by the squids caught from Finisterre to 


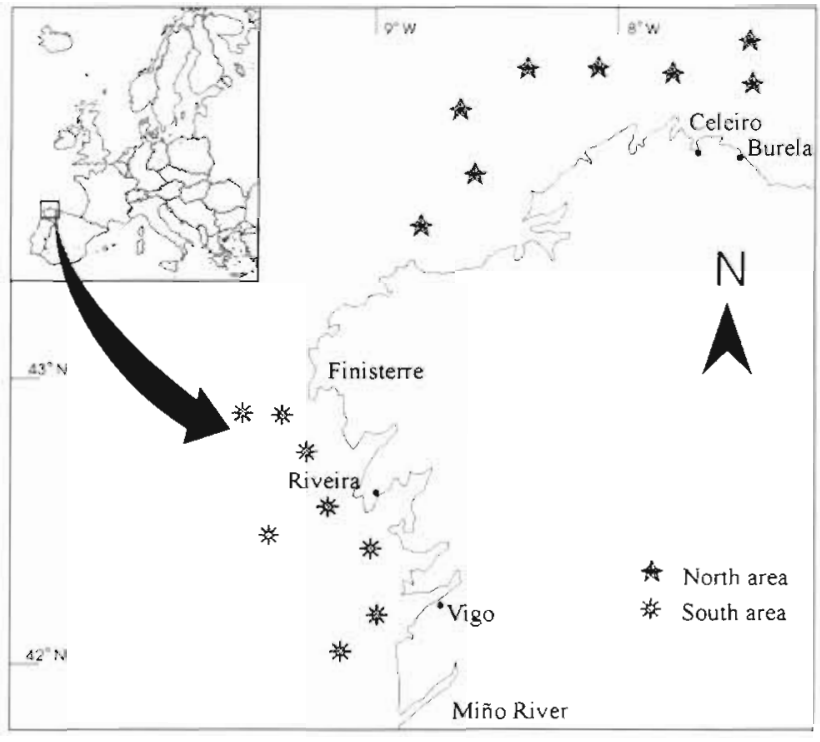

Fig. 1 Location of sampling zones in waters off Galicia (NW Spain)

the Miño river (González et al. 1992) (Fig. 1). Samples of 50 individuals, collected randomly, were sampled each month. For each squid, sex, dorsal mantle length (DML) and total body weight (BW) were recorded. The range of gonad maturity was determined according to an established scale of maturity stages (Lipinsky 1979), but considering stages I and II for males as stage I. The squid were eviscerated inmediately after capture, all organs removed and examined for helminth parasites and the worms counted using a stereomicroscope. For detailed examination, larval nematodes were killed and fixed with Berland' fluid, stored in Loos' fluid, cleared in lactophenol and temporally mounted in glycerine jelly. Plerocercoids were removed, relaxed in tap water, fixed in warm ethanol, stained with Mayer haematoxylin and mounted in Canada Balsam.

The concepts denoted by the terms prevalence, mean intensity, and abundance of infection were defined in accordance with the recommendations of Margolis et al. (1982). To eliminate possible geographic effects, the relationship between host factors and helminth infection was investigated using pooled data from both areas. 'Rare' species (i.e. those with prevalence $<10 \%$; Bush et al. 1990) were not used for statistical analysis. The abundance of infection was transformed as $\log (n+1)$ to reduce the variance (which helped normalize the data; Elliot 1979) and was compared with host-related factors, using the correlation coefficient ( $\mathrm{r}$ ), simple lineal regression and analysis of variance (ANOVA). Probability values $<0.01$ were defined as significant. A class-interval of $20 \mathrm{~mm}$ was adopted, which resulted in a grouping closely corre- sponding with that of squid age-classes. We have followed Weldon \& Slauson (1986) in recognizing one important aspect of regression, the relative importance of the relationship (the proportion of variation associated with the relationship, as measured by $\mathrm{R}^{2}$ ). Data analysis was performed using the SPSS package software (version $\mathrm{H} 9-2$ ).

\section{RESULTS}

Parasites of 5 genera were found (Table 1). The total prevalence in Galician waters of helminth larvae was $48.51 \%(68.24 \%$ in the north and $28.78 \%$ in the south; north: south ratio $=2.37$ ). Tetraphyllidean plerocercoids of Phyllobothrium sp. were the most widespread and abundant helminths, with an overall combined prevalence rate of $45.7 \%$. There were 1 to 115 specimens per squid. Larvae are localized in the organs of the digestive tract (Fig. 2), most commonly found in the lumen of the stomach, caecum and intestine. 'Rare' plerocercoids were also occasionally found parasitizing under the integument of the external wall of the stomach and on the coelomic membrane. In both sam-

Table 1 Illex coindetii. Prevalence (P), mean intensity (I) and abundance $(A)$ of helminth infection in squids caught off NW Spain

\begin{tabular}{|lcccc|}
\hline Parasite species & Locality & P (\%) & I & A \\
\hline Phyllobothrium sp. & North & 61.8 & 11.1 & 9 \\
& South & 27.7 & 2.7 & 1 \\
Dinobothrium sp. & North & $<0.1$ & 2 & $<0.1$ \\
& South & $<0.1$ & 2 & $<0.1$ \\
Pelichnibothrium speciosum & North & $<0.1$ & 1 & $<0.1$ \\
Nybelinia yamagutii & North & $<0.1$ & 2.5 & $<0.1$ \\
Anisakis simplex & North & 19.3 & 5.9 & 2.8 \\
& South & 2.7 & 1.5 & $<0.1$ \\
\hline
\end{tabular}

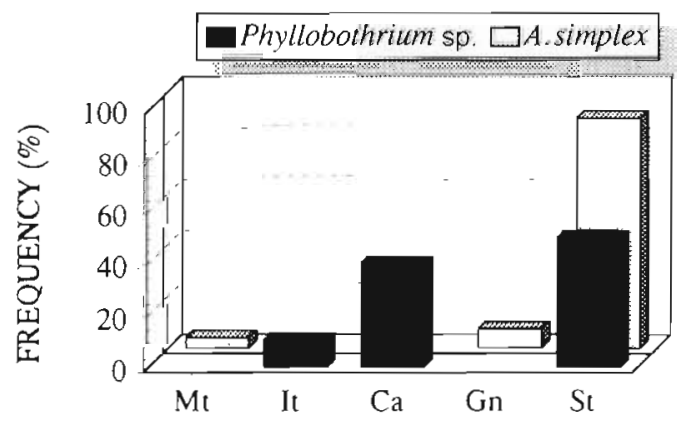

Fig. 2. Illex coindetii. Percentage of organs parasitized by Phyllobothrium sp. and Anssakis simplex in squids from Galician waters. St: stomach; It: intestine; Ca: caecum; Gn: gonad; Mt: mantle cavity 
pling areas, 3 squids had a total of 6 worms belonging to Dinobothrium sp., whereas infection by Nybelinia yamagutii appeared even lower, with only 2 northern parasitized squids. With regard to Pelichnibothrium speciosum, only 1 specimen was found in a single squid. All the nematodes were Anisakis simplex at stage III of development and had the morphological features of that stage (Berland 1961, Pippy \& Van Banning 1975, Grabda 1976. Smith 1983, Orecchia et al. 1986). They measured 12.38 to $23.33 \mathrm{~mm}$ long by 0.1 to $0.5 \mathrm{~mm}$ width. Prevalence was $10.6 \%$ with a mean intensity of 3.8 (range: 1 to 150 ) specimens per squid. They were found encysted on the wall of the stomach and several free individuals were found in the mantle cavity and gonads.

There was no significant relationship between larval infection abundance and squid sex treated either as an independent factor $(F=0.21$; $>0.1$ for Phyllobothrium sp. $) ;(F=5.866 ; \mathrm{p}>0.01$ for Anisakis simplex $)$ or interactively with host maturity $(F=3.240 ; \mathrm{p}>0.01$ for Phyllobothrium sp.); $(F=1.234 ; \mathrm{p}>0.1$ for $A$ simplex $)$. Hence, squid sex was not considered in subsequent analyses and samples from male and female squid were pooled. The results of the correlation and regression analyses of the abundance data showed an increase in the abundance of worms with the length of the host: $(\mathrm{r}=0.7242 ; \mathrm{p}<0.001)\left(\mathrm{R}^{2}=0.454\right.$; ANOVA $F=$ 391.64; $\mathrm{p}<0.001)$ for Phyllobothrium sp.; $(\mathrm{r}=0.512$; $\mathrm{p}<$ $0.001)\left(\mathrm{R}^{2}=0.314 ;\right.$ ANOVA $\left.F=215.42 ; \mathrm{p}<0.001\right)$ for $A$. simplex. Both worm counts increased significantly with host length in all length groups, but the $A$. simplex increase was not as pronounced as that for Phyllobothrium sp. (Fig 3). Abundance of helminth infection also increased as the gonads matured: $(r=0.521$;

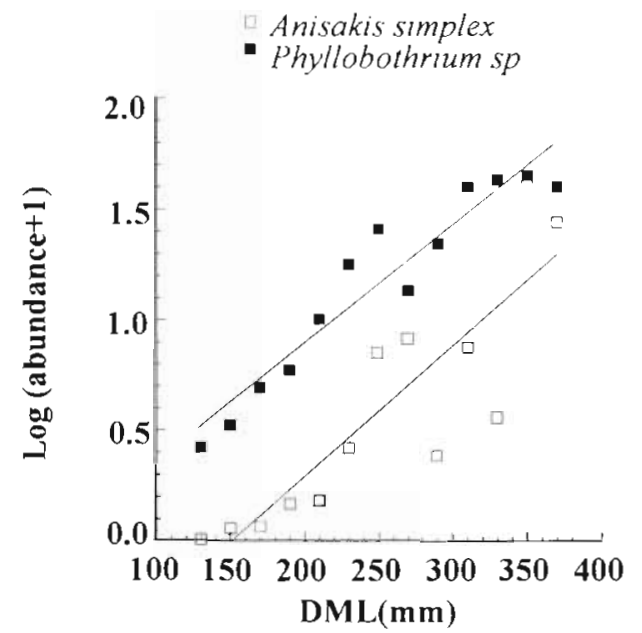

Fig. 3. Illex coindetii. Regression analysis illustrating the pattern of infection attained by helminths in relation to squid length (Anisakis simplex: $y=-0.245+0.119 x, \mathrm{R}^{2}=0.74$ ) (Phyllobothrium sp.: $y=0.413+0.107 x, R^{2}=0.91$ )

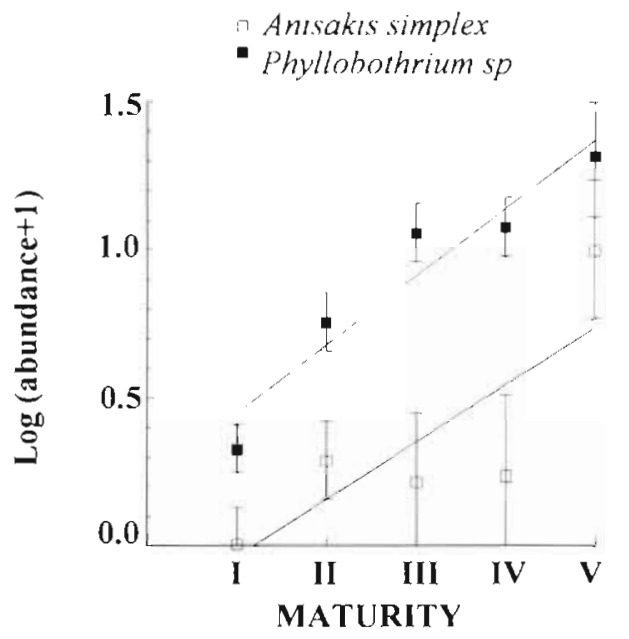

Fig. 4. Illex coindetii. Regression analysis illustrating the pattern of infection attained by helminths in relation to squid maturity (Anisakis simplex: $y=-0.225+0.193 x, R^{2}=0.84$ ) (Phyllobothrium sp.. $y=0.220+0.230 x, R^{2}=0.88$ )

$\mathrm{p}<0.001$ ) (ANOVA $F=28.514 ; \mathrm{p}<0.001$ ) for Phyllobothrium sp; $(\mathrm{r}=0.357 ; \mathrm{p}<0.001)$ (ANOVA $F=$ 14.192; $p<0.001$ ) for $A$. simplex, peaking in ripe and spawning squid (Fig. 4). Nevertheless, maturity classes from the south area were always less parasitized than the corresponding class from the north area.

\section{DISCUSSION}

Analysis of the species composition of helminth parasites from Illex coindetii revealed a homogeneous group of orally acquired endoparasites. It is worthy of notice that all the cosmopolitan parasites (i.e. broad generalist species: Phyllobothrium sp., Anisakis simplex) are 'component' species (sensu Bush et al. 1990) off the northwestern Iberian Peninsula (Guerra 1992). In this sense, we can assume that a typical 'ecological niche-widening' phenomenon (Mas Coma 1991) is taking place here. The increase in host-dependent infection values suggest that the various size-maturity groups of squid apparently take part in different ways in the life cycle of Phyllobothrium sp., being the second and/or third intermediate hosts. However, at least in the case of long-lived digestive parasites, those differences may also simply be due to an accumulation of worms over time as a result of the predatory behaviour of squid (Naidenova et al. 1985).

Anisakis simplex is a parasite mainly of cetaceans and pinnipeds in cold temperate and polar waters (Davey 1971). In the northern Atlantic, this species is widely distributed (Smith 1983) and its larvae are frequently found in squids. The far-neritic coastal distribution of squid and the low level of infection of anisakid 
larvae may explain the paratenic role of squid as host for anisakids.

Mention of the squid's position in the life cycle of rare larval cestodes would, at present, be premature. However, it appears that squid are accidental hosts and infection is connected with the incidental entry into their food of infected prey.

Increasing parasite infection with size and maturity of marine fish hosts is widespread. Cephalopods closely resemble fish in much of their way of life (Packard 1972). Similarly, several aspects of biological interest emerged from the examination of the relationship between squid factors and parasite infection. In host-parasite systems such as Ommastrephid squidcosmopolitan helminths, the parasites usually survive the whole host-life cycle (Hochberg 1990). Accordingly, the number of parasites has been observed to increase with increasing host size. As the size-maturity and age of squid are interrelated (González et al. 1992), a similar trend could be expect-ed between helminth infection and squid age. However, there are often great overlaps in body length between age groups of different 'cohorts' (i.e. a heterogeneous population) in squid stock from Galician waters. Moreover, since similar-sized individuals were of different ages, this parameter must be estimated by examining growth increments in the statoliths. Thus, the relationship may not be straightforward.

Similar results have frequently been observed in other surveys (Shukhgalter 1986, Nigmatullin \& Shukhgalter 1990) and could be explained by behavioural or dietary shifts, increasing host-to-host transfer of parasites through predation. As the ontogenesis of food links occurs, the helminth fauna and quantitative indices of squid infections also change. There was, therefore, no difference in the infection rate of the different sex populations, because preferences for one of the 2 sexes were for hosts of a certain size class.

A clearly local expressed variability of infection was also observed in squids from different ecological sampling areas. The results suggest that infection was related less closely to host size in an area of low infection (south) than in an area with heavier infection (north). Samples from the south area appeared to have a lower level of parasite infection, but this variability is probably partly due to younger mean size of the hosts in these samples. These variations are small and squid length explains much but not all of the variability observed in the abundances (about 91 and $74 \%$ of the variation in the respective data for Phyllobothrium sp. and Anisakis simplex). In fact, differences in life-history characteristics, including age at maturity, growth rate and feeding ecology were also noted between the 2 squid groups along the Galician coast (González et al. 1992). In addition, it is also difficult to say whether these differences are real since different maturity groups of squids within a single sampling area can also have different parasite infection values. The higher levels of parasite infection in squid from the northern area are probably due to peculiarities in the quantitative distribution in that area of infective forms in planktonic animals and fish (the squid prey), the abundance of the final host (the squid predators) and the degree of interchange between all of them via food.

\section{LITERATURE CITED}

Berland B (1961) Nematodes from some Norwegian marine fishes. Sarsia 2:1-50

Bush AO, Aho JM, Kennedy CR (1990) Ecological versus phylogenetic determinants of helminth parasite community richness. Evol Ecol 4:1-20

Davey JT (1971) A revision of the genus Anisakis Dujardin, 1845 (Nematoda: Ascanidata). J Helminthol 45:51-72

Elliot JM (1979) Some methods for the statistical analysis of samples of benthic invertebrates. Freshwater Biological Association Science Publications No. 25

Fraga F, Mouriño C, Manrriquez M (1982) Las masas de agua en la costa de Galicia: Junio-Octubre. Resúmenes Expediciones Científicas 10:51-57

Gaevskaya AV, Nigmatullin Ch M (1975) The helminthofauna of Atlantic squids of the family Ommastrephidae (Cephalopoda:Oegopsida) in relation to features of their ecology. In: Molluscs: their systematic, evolution and role in nature. V. Malacological Congress Izdvo Nauka, Leningrad, p 168-171 (Abstract) (in Russian)

Gaevskaya AV, Nigmatullin Ch M (1977) Distribution of the metacercariae of didymozoid trematodes among Atlantic squids of the family Ommastrephidae. In: All Union Scientific Conference on the Utilization of Commercial Invertebrates for Food. Fodder and Technological purposes, Odessa, p 20-22 (Abstract) (in Russian)

Gaevskaya AV, Nigmatullin Ch M (1978) The helminthofauna of Atlantic squids of the family Ommastrephidae. Malacol Rev 11:20-22

González AF, Rasero M, Guerra A (1992) Illex coindetii and Todaropsis eblanae (Cephalopoda, Ommastrephidae): their present status in Galician Fisheries. Comm Meet int Coun Explor Sea CM/ICES/K:5

Grabda J (1976) The occurrence of Anisakid larvae in Baltic Cod (Gadus morhua callarias L) and the dynamics of their invasion. Acta Ichthyol Piscat 6:1-200

Guerra A (1992) Mollusca, Cephalopoda. In: Ramos et al (eds) Fauna Ibérica, Vol. 1. Museo Nacional de Ciencias Naturales CSIC, Madrid

Guerra A, Pérez-Gándaras G (1983) Las pesquerías mundiales de cefalópodos: situación mundial y perspectivas. Inf Téc Invest Pesq 102-4:1-141

Hochberg FG (1990) Diseases of Mollusca: Cephalopoda. In Kinne $O$ (ed) Diseases of marine animals, Vol. III, Cephalopoda to Urochordata. Biologisches Anstalt Helgoland, Hamburg, p 47-227

Lipinsky M (1979) Universal maturity scale for the commercially important squids (Cephalopoda: Teuthoidea). The results of maturity classification of the Illex illecebrosus (LeSueur, 1821). Populations for the years 1973-1977 ICNAF Research Document Serial No. 5364 79/38, p 40

Margolis L, Esch GW, Holmes JC, Kuris AM, Schad GA (1982) The use of ecological terms in parasitology. J Parasitol 68(1):131-133 
Mas Coma S (1991) The term 'host spectrum widening' Res Rev Parasitol 51 (1-4):189-191

Naidenova NN, Nigmatullin ChM, Gaevskaya AV (1985) The helminth fauna and host-parasite relations of squids Stenoteuthis oualaniensis (Lesson) (Cephalopoda, Ommastrephidae) in the Indian Ocean and the Red Sea. In: Hargis WJ (ed) Parasitology and pathology of marine organisms of the World Ocean. NOAA Technical Report NMFS $25, \mathrm{p} 113-116$

Nigmatullin ChM, Shukhgalter OA (1990) Helmintofauna y aspectos ecológicos de las relaciones parasitarias del calamar (Illex argentınus) en el Atlántico Sudoccidental. Frente Marítimo, Vol. 7, Sec A, p 57-68

Orecchia P, Paggi L, Mattiucci S, Smith JW, Nascetti G, Bullini L (1986) Electrophoretic identification of larvae and adults of Anisakis (Ascaridida: Anisakidae). J Helminthol $68(4): 331-339$

Responsible Subject Editor: W. Körting, Hannover, Germany
Packard A (1972) Cephalopods and fish: the limits of convergence. Biol Rev 47:241-307

Pippy JHC, Van Banning P (1975) Identification of Anisakis larva (I) as Anisakis simplex (Rudolphi, 1809, det Krabbe 1878) (Nematoda: Ascarıdata). J Fish Res Bd Can 32:29-32

Shukhgalter OA (1986) The Argentine squid Illex argentinus as an intermediate host in cestode life cycles. IV AllUnion Conference on Commercial Invertebrates. Abstracts of Proceedings, Sevastopol, p 166-168 (in Russian)

Smith JW (1983) Anisakis simplex (Nematoda:Ascaridoidea): morphology and morphometry of larvae from euphausiids and fish, and a review of the life-history and ecology. $J$ Helminthol 57:205-224

Weldon CW, Slauson WL (1986) The intensity of competition versus its importance: an overlooked distinction. $Q$ Rev Biol 61:23-44

Manuscript first received: July 14, 1994

Revised version accepted: March 28, 1995 